\title{
An empirical study on the effects of different factors on knowledge management systems
}

\author{
Parviz Khadem $^{\mathrm{a}^{*}}$, Rahmatollah Jadidi ${ }^{\mathrm{b}}$ and Mohammad Sadegh Horri ${ }^{\mathrm{c}}$
}

${ }^{a}$ M.A. of Public Management, Islamic Azad University, Arak Branch

${ }^{b}$ Member of Department, Medical Science University of Arak

${ }^{c}$ Member of management Department, Islamic Azad University, Arak Branch

\section{H R O N I C L E A B S T R A C T}

Article history:

Received October 20, 2012

Received in revised format

5 January 2013

Accepted 19 January 2013

Available online

April 242013

Keywords:

Knowledge Management systems

Structural equation modeling

Islamic research center

\begin{abstract}
Knowledge management plays an essential role on achieving business success and it is considered as intangible attests for many organizations. In fact, many people believe intangible assets are the most influential part of any firm's investment. This paper investigates the relationships among four variables including empowering leadership, task technology fit, compatibility and knowledge management system (KMS). The study considers whether there is any positive relationship between empowering leadership and task technology fit, between empowering leadership and compatibility, between task technology fit and KMS usage and between compatibility and KMS usage. The survey selects a sample of 215 people from the regular employees as well as university professors of Islamic research center of Qom province, Iran. We have distributed 220 questionnaires and collected 160 for the investigation. The results of this survey indicate that there is a meaningful and positive relationship between empowering leadership and compatibility $(0.72, \mathrm{t}$-student $=4.01)$, a meaningful and positive relationship between empowering leadership and compatibility $(0.80, t$-student $=4.64)$, a positive and meaningful relationship between task technology fit and KMS usage $(0.72$, t-student $=3.58)$ and finally there is a positive and meaningful relationship between compatibility and KMS usage (0.43, t-student $=2.78)$.
\end{abstract}

\section{Introduction}

Knowledge plays an essential role on the success of organizations, and its effective management is, therefore, an important component for maintaining organizational competitive advantage. There are an increasing number of organizations engaged in knowledge management initiatives and making significant investments in deploying knowledge management system (KMS) to help organizations recognize knowledge management activities, efficiently (O’Brien \& Marakas, 2006; Hahn \& Wang,

\footnotetext{
*Corresponding author.

E-mail addresses: syahkaly@gmail.com (P. Khadem)

(c) 2013 Growing Science Ltd. All rights reserved. doi: 10.5267/j.msl.2013.04.025
} 
2009). Today, many organizations must equip themselves to adopt KMS and confront the challenges posed by such activities.

Kuo et al. (2011) attempted to identify the specific managerial behaviors associated with adoption success. They tried to explore the impact of empowering leadership on knowledge management system (KMS) adoption through its impacts on task-technology fit and compatibility. They reported that empowering leadership had an indirect impact on KMS usage while empowering leadership was positively associated with both task-technology fit and compatibility and both of them were positively associated with KMS usage.

Information system (IS) is normally designed to store large amounts of information and automatically arrange them into specific formats and outcomes to facilitate operational management achievement. However, KMS is designed to efficiently help organizational KMS, which is a kind of IS supporting knowledge management processes associated with the creation, storage/ retrieval, and application of knowledge within and outside an organization (Alavi \& Leidner, 2001). In other words, KMS is an important of firm's capability to apply its existing knowledge while attempting to generate new knowledge. With an effective KMS in place, management can optimize its organizational knowledge resources by utilizing, accumulating, sharing, and creating them.

There is no doubt that KMS cannot be considered as a general-purpose IS and it is a system, which is capable of keeping the patterns of knowledge practices and further utilization (Butler et al., 2008; Mcdermott, 1999; Nonaka et al., 1998). This means that the success of KMS could allow system to be consistently compatible with the work styles of its users (Teo \& Men, 2008). On the other hand, the primary objective of knowledge management is to facilitate efforts to manage knowledge as efficiently as possible and KMS requires to incorporate the suitable information/knowledge to clearly help user reach his/her needs (Kuo \& Lee, 2009; Liu \& Wu, 2008). Therefore, for an appropriate implementation of KMS for the knowledge management applications, design perspectives do not have to be limited to fulfill the user tasks' needs (Hahn \& Wang, 2009; Lin \& Huang, 2008; Liu \& $\mathrm{Wu}, 2008$ ) but it should be consistent with the user's work style (Butler et al., 2008; Teo \& Men, 2008). A well designed KMS could facilitate the organization's tasks in leveraging and managing knowledge, increasing the knowledge management advantages.

There are different advantages for the effective use of KMS but there still various firms complaining of not reaching good outcomes of KMS implementation (Hahn \& Wang, 2009; Quigley et al., 2007; Wasko \& Faraj, 2005). However, getting employees to implement the KMS to improve knowledge management performance is still an open subject among many researchers and practitioners (He et al., 2009; Jennex \& Olfman, 2004; Lin \& Huang, 2008; Wu \& Wang, 2006).

Without consistent employee use of KMS, the system becomes ineffective as a knowledge management solution (Nevo \& Chan, 2007). Therefore, understanding how best to adopt a KMS within an organization successfully remains a high priority, especially since management have made large efforts and expenditures to take knowledge management initiatives (Poston \& Speier, 2005).

This paper investigates the relationships among four variables including empowering leadership, task technology fit, compatibility and knowledge management system (KMS). The organization of this study first presents details of the problem statement in section 2 and section 3 presents the results of our survey. Finally, concluding remarks are given in the last to summarize the contribution of the paper.

\section{The proposed model}

The proposed study of this paper uses the following framework to investigate the relationships among four variables including empowering leadership, task technology fit, compatibility and knowledge management system (KMS). Fig. 1 shows details of the implementation of our proposed model. In 
this survey, we collected a sample of 215 people from the regular employees as well as university professors of Islamic research center of Qom province, Iran. We have distributed 220 questionnaires and collected 160 for the investigation.

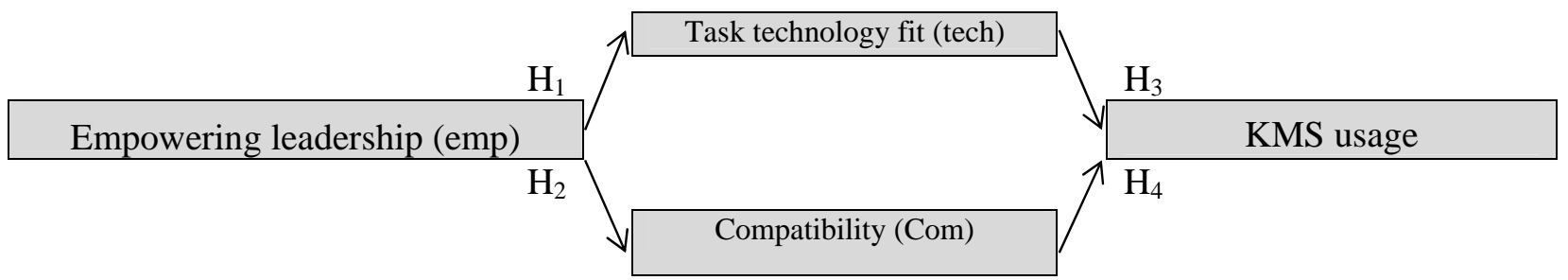

Fig. 1. The framework of the proposed model (Kuo et al., 2011)

Cronbach alpha has been calculated for four components of the survey and the results are summarized in Table 1 as follows,

Table 1

The summary of Cronbach alpha

\begin{tabular}{lccc}
\hline & Cronbach alpha & Samples & Questions \\
\hline Empowering leadership & 0.684 & 160 & 4 \\
Compatibility & 0.640 & 160 & 3 \\
Task technology fit & 0.700 & 160 & 8 \\
KMS usage & 0.600 & 160 & 5 \\
\hline
\end{tabular}

The proposed study of this paper uses Structural Equation Models (SEM) to analyze the data and Confirmatory Factor Analysis (CFA) to validate the results. The survey considers the following four hypotheses,

1. There is a positive relationship between empowering leadership and task technology fit.

2. There is a positive relationship between empowering leadership and compatibility.

3. There is a positive relationship between task technology fit and KMS usage.

4. There is a positive relationship between compatibility and KMS usage.

\section{The results}

As we have explained earlier, we have used SEM to study the relationships between four different components of this survey and Table 2 demonstrates the summary of our findings associated with the data.

\section{Table 2}

The summary of statistical observations associated with the implementation of SEM

\begin{tabular}{lcc}
\hline Statistics & Standard value & Observed value \\
\hline Degrees of Freedom & - & 101 \\
Chi-Square & - & 360.49 \\
RMSEA & 0.05 & 0.083 \\
NFI & 0.90 & 0.81 \\
NNFI & 0.90 & 0.87 \\
CFI & 0.90 & 0.89 \\
RMR & 0.05 & 0.068 \\
GFI & 0.90 & 0.82 \\
AGFI & 0.90 & 0.77 \\
\hline
\end{tabular}


As we can observe from the results of Table 2, all components remained within acceptable values, we may use these results of SEM implementation, and Fig. 2 and Fig. 3 demonstrate the results in terms of standard values as well as t-student components.

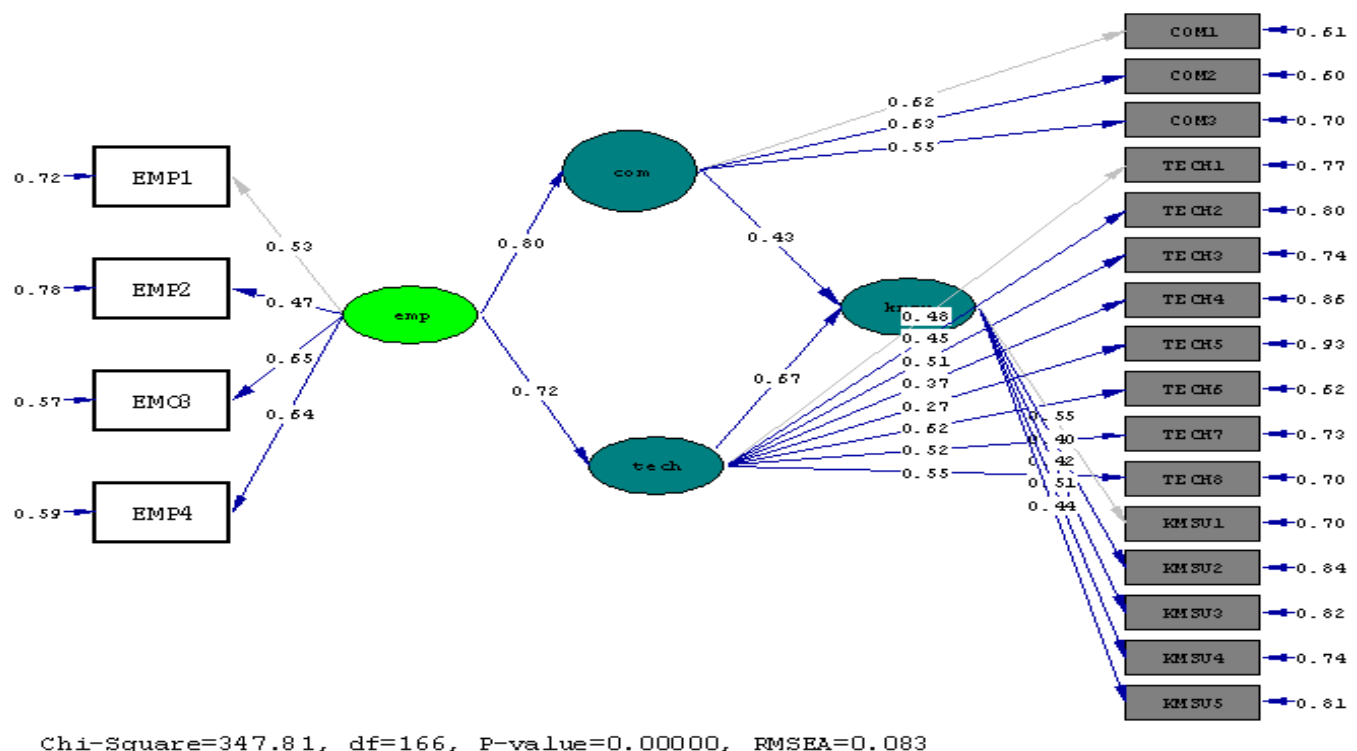

Fig. 2. T-student values

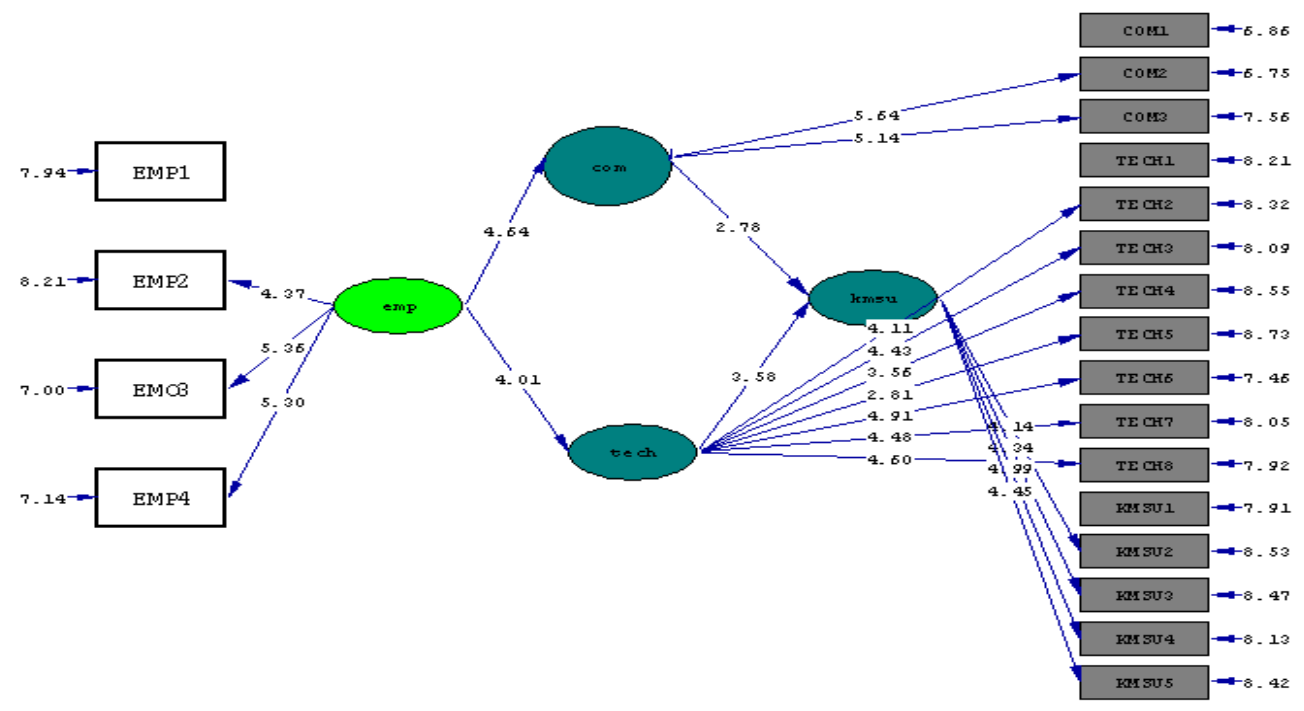

Chi-Square=347.81, df=166, P-value=0.00000, RMSEA $=0.083$

Fig. 3. Standard values

Statistical observation for SEM implementation yields indicate that P-value is equal to 0.0000, which means the observations are statistically significant. In addition, Chi-Square/df $=2.09$, which also indicates that the results are reliable. 
As we can observe from the result of Fig. 2 and Fig. 3, there is a meaningful and positive relationship between empowering leadership and compatibility $(0.72$, t-student=4.01) and the first hypothesis is confirmed. The second hypothesis is associated with the relationship between empowering leadership and compatibility. Again, the results of Fig. 3 demonstrates that there is a meaningful and positive relationship between empowering leadership and compatibility $(0.80$, t-student $=4.64)$ and the first hypothesis is confirmed. The third hypothesis studied the 1. relationship between task technology fit and KMS usage and according to what we can observe from Fig. 2 and Fig. 3, there is a positive and meaningful relationship between these two components $(0.72$, t-student=3.58). Finally, the last hypothesis of this paper confirms the relationship between compatibility and KMS usage (0.43, tstudent=2.78).

\section{Conclusion}

In this paper, we have investigated the relationships among four variables including empowering leadership, task technology fit, compatibility and knowledge management system (KMS). The study has examined whether there is any positive relationship between empowering leadership and task technology fit, between empowering leadership and compatibility, between task technology fit and KMS usage and between compatibility and KMS usage using a sample of 215 people from the regular employees as well as university professors of Islamic research center of Qom province, Iran. The results of this survey have indicated that there was a meaningful and positive relationship between empowering leadership and compatibility $(0.72$, $t$-student $=4.01)$, a meaningful and positive relationship between empowering leadership and compatibility $(0.80$, t-student $=4.64)$, a positive and meaningful relationship between task technology fit and KMS usage $(0.72$, t-student $=3.58)$ and finally there is a positive and meaningful relationship between compatibility and KMS usage (0.43, tstudent=2.78).

\section{Acknowledgment}

The author would like to thank the anonymous referees for constructive comments on earlier version of this work.

\section{References}

Alavi, M., \& Leidner, D.E. (2001). Review: knowledge management and knowledge management systems: conceptual foundations and research issues. MIS Quarterly, 25(1), 107-36.

Butler, T., Feller, J., Pope, A., Emerson, B., \& Murphy, C. (2008). Designing a core IT artefact for knowledge management systems using participatory action research in a government and a nongovernment organization. The Journal of Strategic Information Systems, 17(4), 249-67.

Hahn, J., \& Wang, T. (2009). Knowledge management systems and organizational knowledge processing challenges: a field experiment. Decision Support Systems, 47(4), 332-42.

He, W., Qiao, Q., \& Wei, K.-K. (2009). Social relationship and its role in knowledge management systems usage. Information \& Management, 46(3), 175-80.

Jennex, M.E., \& Olfman, L. (2004). Assessing knowledge management success/effectiveness models. Proceedings of the 37th Annual Hawaii International Conference on System Sciences, IEEE Computer Society, Piscataway, NJ.

Kuo, R.Z., Lai, M.F., \& Lee, G.G. (2011). The impact of empowering leadership for KMS adoption. Management Decision, 49(7), 1120-1140.

Lin, T.-C., \& Huang, C.-C. (2008). Understanding knowledge management system usage antecedents: an integration of social cognitive theory and task technology fit. Information \& Management, 45(6), 410-417.

Liu, D.-R., \& Wu, I.C. (2008). Collaborative relevance assessment for task-based knowledge support. Decision Support Systems, 44(2), 524-543. 
McDermott, R. (1999). Why information technology inspired but cannot deliver knowledge management. California Management Review, 41(4), 103-17.

Nonaka, I., Reinmoeller, P., \& Senoo, D. (1998). The 'Art' of knowledge: systems to capitalize on market knowledge. European Management Journal, 16(6), 673-84.

O’Brien, J.A., \& Marakas, G.M. (2006). Management Information Systems. th $_{\text {th }}$ ed., McGraw-Hill, International, New York, NY.

Teo, T.S.H., \& Men, B. (2008). Knowledge portals in Chinese consulting firms: a task-technology fit perspective. European Journal of Information Systems, 17(6), 557-74.

Quigley, N.R., Tesluk, P.E., Locke, E.A., \& Bartol, K.M. (2007). A multilevel investigation of the motivational mechanisms underlying knowledge sharing and performance. Organization Science, 18(1), 71-88.

Wasko, M.M., \& Faraj, S. (2005). Why should I share? Examining social capital and knowledge contribution in electronic networks of practice. MIS Quarterly, 29(1), 35-57.

Wu, J.-H., \& Wang, Y.-M. (2006). Measuring KMS success: a respecification of the Delone and Mclean's model. Information \& Management, 43(6), 728-39. 